\title{
Interés geoestratégico de las Islas Baleares y actividades de reconocimiento aéreo de la Royal Air Force (1941-1944)
}

\author{
Geostrategic interest of the Balearic Islands \\ and aerial reconnaissance by the Royal Air Force (1941-44)
}

\author{
Celso García ${ }^{1^{*}}$ (iD \\ Antoni Ginard-Bujosa ${ }^{2}$ (i) \\ Joana M. Petrus ${ }^{3}$ (1)
}

\section{Resumen}

La localización geoestratégica de las Baleares en el centro de la cuenca occidental del Mediterráneo, y su utilidad como base naval y aérea, ayudó a que las islas fueron observadas y vigiladas por las fuerzas del eje y los aliados durante la segunda guerra mundial. Desde octubre de 1941 hasta marzo de 1944 las Baleares fueron objeto de un minucioso seguimiento a través de las fotografías aéreas verticales realizadas por vuelos de reconocimiento de las fuerzas aéreas británicas que salían desde Gibraltar. Estas fotografías eran utilizadas para realizar informes al gabinete de guerra sobre la situación en los puertos y aeródromos de las islas. Además, las diversas imágenes fotográficas, que tenían un grado de resolución muy elevado, fueron utilizadas en los informes especiales de interpretación para cada isla. Estos estudios técnicos de fotointerpretación realizan un análisis territorial exhaustivo, idóneo para una eventual ocupación militar. Las fotografías aéreas descubiertas son de gran interés, porque, mediante la georeferenciación, hacen posible los estudios geomorfológicos, biogeográficos, de usos del suelo, de cultivos, de la red viaria, de las infraestructuras, de la evolución urbana, $\mathrm{o}$, incluso, de las primeras instalaciones turísticas a principios de la década de 1940.

Palabras clave: Islas Baleares; fotografía aérea histórica; vuelos de reconocimiento aéreo; informes de fotointerpretación; geopolítica; segunda guerra mundial.

\footnotetext{
Abstract

The location of the Balearic Islands in the centre of the western Mediterranean and their usefulness as a naval and air base, was an important factor for the observation and monitoring of the islands by the Axis and Allied forces. From October 1941 to March 1944, the Balearic Islands were closely monitored through aerial photographs taken by the British Royal Air Force in reconnaissance flights departing from Gibraltar. These photographs were used to report to the war cabinet on the situation in the ports and airfields. In addition, high-resolution photographic images were used in special interpretation reports for each island. These technical photo-interpretation studies were part of an exhaustive territorial analysis in preparation for a military occupation. The discovered historical aerial photos are of great interest because, by means of georeferencing, it is possible to analyse the historical evolution of the geomorphology

1 Departamento de Geografía, Universitat de les Illes Balears, 07122 Palma, Balears, España. celso.garcia@uib.es. * Autor para correspondencia

2 Departamento de Geografía, Universitat de les Illes Balears, 07122 Palma, Balears, España. antoni.ginard@uib.es

3 Departamento de Geografía, Universitat de les Illes Balears, 07122 Palma, Balears, España. joana.petrus@uib.es 
(coastline and beach-dune systems), biogeography (vegetation and wetlands), land use, infrastructures (including ports and airports), urban development, and even the first tourist facilities at the beginning of the 1940s.

Keywords: Balearic Islands; historical aerial photos; aerial reconnaissance; geopolitics; special interpretation reports; Second World War.

\section{Introducción}

$\mathrm{Al}$ acabar la década de 1930, en un contexto internacional en el que se vislumbraba un nuevo enfrentamiento bélico, los planteamientos teóricos de la geopolítica del Eje (Alemania e Italia) en relación al sur de Europa y, en concreto, en el Mediterráneo occidental, eran objeto de atención y de estudio desde el punto de vista británico, tanto para la salvaguarda de sus propios intereses como para evaluar las intenciones y las posibilidades de los adversarios (Liddell Hart, 1939).

Así, según la perspectiva británica, el plan político y militar de Alemania en el Mediterráneo, en base a la geografía, afectaba los intereses y las rutas comerciales de Gran Bretaña, Italia, Francia, sus territorios del norte de África, y la Península Ibérica, principalmente Cataluña y las islas Baleares.

De acuerdo con las pautas del expansionismo alemán, los británicos analizaban especialmente los objetivos y la estrategia de las actividades alemanas e italianas en el Mediterráneo occidental y su incidencia en los esquemas de los intereses del Imperio británico.

El significado estratégico del mar Mediterráneo derivaba de su dimensión compacta y de las barreras naturales capaces de proteger los enlaces con otros mares, pero también de la distribución de los grupos de las islas centrales (Baleares, Córcega y Cerdeña), que podrían ser baluartes marítimos o puestos avanzados desde los que lanzar ataques. Estos lugares eran de vital importancia para el control y la seguridad de las vías marítimas que unían las metrópolis coloniales y las respectivas zonas de expansión en el norte de África y hacia Oriente. El mantenimiento del Imperio británico dependía de las rutas marítimas. Estratégicamente, el mar Mediterráneo era un canal de 2.000 millas entre Port Said-Alejandría y Gibraltar. En este extenso corredor marítimo, el Reino Unido controlaba las islas de Malta y de Chipre y el canal de Suez. La ruta hacia el Este y el Extremo Oriente a través del canal de Suez era para Gran Bretaña una parte integral del Imperio Británico, uno de los enlaces esenciales de su sistema político y económico. Otra arteria vital era la conexión de Francia con sus posesiones coloniales en el norte de África (Liddell Hart, 1939).

Los autores alemanes de los estudios teóricos geopolíticos asumían la expansión de Italia casi como una necesidad biológica, para la obtención de materias primas y para dar salida al exceso de población y a la producción industrial y agrícola (Fioravanzo, Bauerkämper y Rossoliński-Liebe, 2017. Para ser una gran potencia y alcanzar la supremacía en el Mediterráneo, Italia debía apoyarse en otra gran potencia, que únicamente podía ser Alemania. Los objetivos de la Italia fascista en el Mediterráneo coincidían pues, punto por punto, con los de la Alemania nazi: en cierta manera, cualquier avance italiano en el Mediterráneo era un avance alemán.

Según los analistas británicos, el dominio italiano de la línea diagonal insular Baleares, Cerdeña, Sicilia suponía el control de Italia sobre la ruta comercial al Extremo Oriente. Al mismo tiempo, significaba acorralar militar, política y económicamente a Francia y la ruptura de las comunicaciones con Argelia y Túnez (y la probable pérdida de ambos territorios). Este control italiano del Mediterráneo significaba que Francia, a su vez, tendría que ceder a la presión italiana en algunos puntos vitales, Córcega entre ellos, pues una Córcega francesa era una amenaza para Italia, que tampoco había renunciado a Niza ni a Saboya. En ese sentido, no puede ignorarse que Malta y Córcega fueron objetivos estratégicos para Mussolini en su afán de convertir el «Mare nostrum» en escenario del nuevo renacimiento italiano, pues la difícil integración de ambas islas en el imperio británico y en el estado francés, respectivamente, las hacía vulnerables a las reivindicaciones territoriales que desde 1923 lanzó contra ellas el régimen fascista italiano (Paci, 2013). Finalmente, la seguridad de Gran Bretaña estaba interrelacionada con la de Francia, a causa de la contigüidad geográfica, pero también por la doble fachada marítima de Francia (atlántica y mediterránea) y por la posición francesa en el Mediterráneo y el mantenimiento de sus dependencias en el norte de África. Por ello, la política exterior británica estaba ligada a la de Francia.

España, entonces gobernada por el régimen dictatorial del general Franco, era un aliado natural del Eje, en especial de Alemania contra Francia. Alemania tenía interés en una España fuerte, porque ampliaba la 
frontera que Francia debía defender y le obligaba a mantener cuerpos de ejército en los Pirineos, lejos de la frontera del Rin. El incremento del potencial de Alemania y de España estaba ligado a la debilidad de Francia. España, incapaz de permanecer neutral en un conflicto mediterráneo, había tenido la posibilidad de elegir a favor o en contra de Francia. La victoria del general Franco reduciría la elección a una sola opción.

La situación geográfica de la Península Ibérica le otorgaba una posición estratégica de primer orden. Según los teóricos alemanes, la actitud de España era de primordial importancia en cualquier conflicto en el Mediterráneo. España tenía la llave del extremo occidental del canal del mar Mediterráneo, sobre todo porque comprometía la función de Gibraltar (una vieja reclamación territorial española) como base naval y las conexiones de Gran Bretaña con el lejano extremo de levante del Mediterráneo. La sola posibilidad que las bases aéreas y navales en la costa oriental de España y en las islas Baleares pudiesen estar disponibles para el uso de los adversarios complicaría seriamente el mantenimiento del tránsito - tanto el paso seguro de alimentos y materias primas como el movimiento de tropas - en el Mediterráneo, al tiempo que pondría en peligro las comunicaciones entre Francia y sus colonias africanas, ya que la mayor parte de las rutas marítimas estaban al alcance de las bases españolas.

Según el británico Liddell Hart (1939), ${ }^{4}$ España estaba cerca de la intersección de las principales comunicaciones del Imperio británico; en caso de guerra, para asegurar las rutas marítimas, la amistad de España era deseable, pero una España neutral era vital. Cataluña era el área de mayor interés geopolítico de la Península Ibérica, ${ }^{5}$ por ser la puerta de entrada mediterránea de la Península y por tener vías de acceso abiertas hacia Francia. Barcelona era un punto central muy importante para el tránsito a la cuenca occidental del Mediterráneo. Una gran Cataluña (es decir, las áreas de lengua catalana de Valencia y Cataluña), constituida como un Estado independiente, podría proporcionar un puente terrestre (considerando, así mismo, hasta el puerto de Cartagena), que uniese Francia con su imperio de África del Norte. Por otra parte, Cataluña constituía una unidad estratégica con las islas Baleares. El territorio de Cataluña también se veía amenazado por la expansión de Italia.

Si una Cataluña libre podría ser de gran importancia para la seguridad de Francia, la España del régimen del general Franco - en consonancia con los intereses alemanes- no podía permitir un Estado catalán independiente. Incluso, para mantener a los catalanes bajo el dominio castellano y fomentar la expansión de España, se planteaba que la capital del nuevo Estado español habría de cambiarse de Madrid a Barcelona. Esto situaría a los kingdom-makers [sic] castellanos más cerca de un nuevo foco de poder en la intersección de comunicaciones terrestres y marítimas cruciales, incluido el previsto Canal des Deux Mers, a través del Midi francés, desde el Atlántico al Mediterráneo que estaba a punto de convertirse en un mar de acontecimientos decisivos (Liddell Hart, 1939).

En este contexto geopolítico, la posición geográfica de las islas Baleares adquiría una significación estratégica capital, por su situación en el centro de la cuenca occidental del Mediterráneo, como base naval y aérea, tanto para proteger como para atacar rutas marítimas vitales. En particular, su papel se había visto igualmente reforzado como nudo de comunicaciones aéreas. De hecho, desde la mitad de la década de 1930, Mallorca fue un punto de escala para la compañía aérea italiana Ala Littoria (con una línea Roma-Pollensa-Melilla-Cádiz) y para la compañía Air France (entre Marsella y Argel).

La importancia de las islas Baleares se explica por diversos factores (Liddell Hart, 1939):

- Respecto a la posición naval de Francia, por su ubicación, en una bahía del sur de Francia, que alcanza las islas Baleares y Córcega, podían cortar las comunicaciones francesas con el norte de África.

- En cuanto a Italia, a través de la línea diagonal insular Baleares, Cerdeña, Sicilia, los alemanes eran conscientes de que un ataque italiano no podía ser completo y tener éxito sin controlar las Baleares, desde donde las fuerzas italianas podrían amenazar las rutas coloniales francesas y británicas, Gibraltar incluido.

- En función de la situación de Cataluña, las islas Baleares formaban una unidad estratégica con Cataluña, hasta el punto que el control de Menorca y de Cataluña por una misma potencia hacía inútil la posesión de Mallorca por otra potencia. El triángulo Barcelona, Cartagena, puerto de Mahón cortaba las rutas marítimas francesas hacia el norte de África.

4 Sir Basil Henry Liddell Hart (31 de octubre de 1895 - 29 de enero de 1970), conocido como capitán Basil Liddell Hart, fue un militar, historiador militar, teórico militar y periodista inglés.

5 Es obvio que los teóricos de la geopolítica tenían en cuenta la situación de Cataluña durante la Segunda República española (19311936) y la oposición catalana al bando nacional durante la guerra civil (1936-1939). 
- Desde el punto de vista británico, siempre pendiente de la protección de Gibraltar, del Estrecho y de la ruta del Extremo Oriente, era de vital importancia el control (en las manos adecuadas) de las Baleares y de la costa española. No por casualidad, durante años, las maniobras de la flota mediterránea británica se habían efectuado habitualmente en aguas de las Baleares.

Durante la segunda guerra mundial, en el marco de la lucha por el control estratégico de la cuenca occidental del Mediterráneo, los aviones de reconocimiento fotográfico de la Royal Air Force británica (RAF) y de los aliados efectuaron misiones sobre las islas Baleares, fundamentalmente entre 1941 y 1944. Lógicamente, los ejércitos de las potencias del Eje dispusieron de equipos aéreos de reconocimiento y también efectuaron misiones fotográficas sobre el archipiélago. Al final de la guerra, los aliados formaron unidades especiales para recuperar - $\mathrm{y}$ aprovechar en beneficio propio- los archivos fotográficos del ejército alemán en lo que se denominó «Operación Dick Tracy» (Aldrich, 1998). El botín fueron cientos de cajas con fotografías aéreas de $12 \times 12$ pulgadas y documentos con planos de ciudades, mapas de salidas, etc. (Williams, 2013). En el caso de los Aliados, al acabar la guerra en Europa con la rendición de Alemania en mayo de 1945, algunos de los aviones de bombardeo de la United States Army Air Forces (USAAF) no se destinaron al Pacífico, donde la guerra aún continuaría varios meses, sino que quedaron en el continente. Conjuntamente con la RAF británica, la fuerza aérea norteamericana se distribuyó sobre el territorio europeo y diseñó un vuelo con el objetivo de obtener una cobertura fotográfica de toda Europa y el norte de África para mejorar la información de la que se disponía y corregir así los mapas topográficos existentes. Esta operación fue conocida como «Operación Casey Jones» (Boyd, 2016). Este vuelo, conocido en España como «vuelo americano de la serie A: 1945-46» (Fernández García y Quirós Linares, 1997), puede consultarse en la fototeca del Instituto Geográfico Nacional y permite su visualización para la península pero no proporciona imágenes de ninguno de los dos archipiélagos.

De esta forma, se viene considerando que la fotografía aérea más antigua de que se dispone de las islas Baleares es la realizada por el vuelo comercial realizado en 1956-57 («Vuelo Americano, serie B»). Sin embargo, la investigación realizada en distintos archivos británicos y estadounidenses han permitido hallar un nuevo conjunto de fotografías aéreas correspondientes al período 1941-44 realizadas por las fuerzas aéreas de los aliados. ${ }^{6}$

En efecto, durante el desarrollo de la segunda guerra mundial, las fuerzas aéreas aliadas, británicas inicialmente y luego conjuntas con las estadounidenses, realizaron centenares de misiones de reconocimiento aéreo que cubrían desde distintos puntos de salida todo territorio europeo y el norte de África. El objetivo de estas misiones era la estrecha vigilancia de localizaciones concretas, como puertos y aeródromos, arsenales, construcciones defensivas, carreteras, puentes, etc. para tratar de advertir en ellos actividades que pudieran revelar movimientos de tropas de manera especialmente intensa - desde finales de 1941 a principios de 1944_, el interés de los lugares y enclaves cambiaban conforme el devenir de los acontecimientos durante el transcurso de la segunda guerra mundial.

Los resultados de los reconocimientos aéreos — conocidos en parte- son diferentes series de fotografías aéreas, con el consiguiente trabajo de los equipos de interpretación, que pueden aportar una valiosa información para el conocimiento del territorio. A pesar de que las operaciones aéreas tenían una finalidad de carácter militar, el estudio de las imágenes y de la información que generaron es muy útil para un análisis territorial y también evolutivo de las zonas que fueron objeto de cobertura por fotografía aérea (p.e.: Fernández García, 2012, 2015; Urteaga, Nadal y Muro, 2000).

El objetivo de este trabajo es mostrar la cantidad de información que se obtuvo a partir de salidas de reconocimiento fotográfico, que se realizaron desde Gibraltar, con el objetivo de obtener imágenes aéreas verticales que permitieran su posterior fotointerpretación y análisis de los lugares con un interés geoestratégico: principalmente puertos y aeropuertos. Las islas Baleares fueron objeto de un minucioso seguimiento desde octubre de 1941 hasta marzo de 1944. En el caso de la isla de Mallorca, a partir de la documentación consultada, se contabilizan hasta 22 salidas de reconocimiento fotográfico aéreo, 10 sobre Menorca y 6 sobre la isla de Ibiza.

6 Para las islas Canarias, las fotografías aéreas históricas que se vienen considerando más antiguas corresponden al vuelo fotogramétrico realizado por el Centro Cartográfico y Fotográfico (CECAF) fechado entre los años 1951 y 1957. Este vuelo registró la totalidad del archipiélago a excepción de Tenerife del que sólo se dispone del vuelo de costa. Los hallazgos de fotografía aérea de la IIGM que se aporta en esta investigación permiten afirmar la existencia de fotogramas de las islas Canarias más antiguas a éstas. 


\section{Metodología}

Los archivos británicos, en particular The National Archives (Londres) y The National Collection of Aerial Photography (Edinburgo) custodian la documentación y las imágenes fotográficas generadas por los vuelos de reconocimiento aéreo efectuados por las fuerzas aliadas durante la segunda guerra mundial. Con la intención de rastrear la información relacionada con las islas Baleares (en ocasiones sin catalogar), también se realizaron consultas en los fondos de otros archivos, como los británicos Imperial War Museum $o$ Medmenham Association \& Collection; asimismo, The Cartographical and Architectural Section of the United States National Archives \& Records Administration (NARA) o el Australian War Memorial; igualmente, los archivos del Centro Cartográfico y Fotográfico del Ejército del Aire y del Instituto Geográfico Nacional (IGN).

En la documentación histórica consultada se han obtenido referencias directas a las operaciones militares diseñadas a partir de los informes secretos que se realizaban en la base de Medmenham, fruto de la fotointerpretación de las imágenes aéreas tomadas a través de los vuelos de reconocimiento fotográfico. Este trabajo destaca parte de la información obtenida en estos archivos, que permite demostrar el interés geoestratégico de las Baleares entre 1941 y 1944. De los documentos históricos consultados en The National Archives en Londres se obtuvieron los datos de las salidas de reconocimiento fotográfico, la mayoría procedentes de Gibraltar (identificados con la letra G delante del número de salida). Una vez obtenida esta información, se consultó con The National Collection of Aerial Photography (NCAP) en Edimburgo para averiguar si disponían del fondo de fotografías aéreas con estos números de salidas. Desgraciadamente, el NCAP no conserva ninguna fotografía aérea con estos registros de salidas sobre las Baleares, aunque sí dispone de fotografías con las salidas realizadas para la Secretaría de Guerra del Ministerio de Defensa (WO/War Office), las cuales tomaron fotografías aéreas de Mallorca y Menorca. Estos datos fueron localizados finalmente en el archivo nacional americano NARA, que conserva algunas fotos de las primeras salidas, como la G47 del 21 de octubre de 1941 sobre la isla de Ibiza y la bahía de Palma y de la del 22 de octubre sobre el puerto de Mahón.

Además de las fotografías, y a modo de ejemplo, la consulta de las reuniones del Gabinete de Guerra británico, presidida por Winston Churchill, permiten corroborar que el 20 de mayo de 1940 (justo diez días después de asumir el cargo de primer ministro, el 10 de mayo de 1940), se informaba en secreto que la situación en España "se movía rápidamente". ${ }^{7}$ De hecho, Alemania ya había invadido Francia; Italia estaba a punto de entrar en la guerra; a pesar de todo, a la larga, la expansión hacia el este de Europa sería una prioridad para el ejército alemán.

Los estrategas militares actuaban con la previsión de cualquier escenario hipotético y preparaban una posible respuesta para hacer frente a cualquier eventualidad. Un ejemplo de ello aparece en el memorándum secreto norteamericano Study of Certain Terrain and Logistics Aspects of the Iberian Peninsula [and Balearic Islands] de 12 de diciembre de $1942 .{ }^{8}$ Es un estudio logístico y del terreno hecho para la planificación estratégica y como base de un plan para la ocupación de la Península Ibérica. En este documento, los norteamericanos asumen, entre otros aspectos, el hipotético escenario en que las divisiones alemanas hayan ocupado la Península; que España es beligerante, al lado del Eje; que la población de Portugal — sometido a la ocupación del Eje — es favorable a los aliados, y que Gibraltar haya sido capturado o neutralizado. Aunque las islas Baleares aparezcan en el título, el memorándum no trata de las islas de una manera específica (quizás porque se centraba en un plan de ocupación terrestre).

\section{Resultados}

\subsection{Los reconocimientos aéreos en las Baleares}

Los fundamentos de la planificación estratégica comienzan siempre por la información (espionaje, infiltración, contactos, contra información, conocimiento del terreno, etc.). Con el objetivo de recopilar información, por su interés geoestratégico, las islas Baleares fueron objeto de las actividades de reconocimiento aéreo de la RAF y de los aliados (especialmente a partir de 1941) (Massot i Muntaner, 1995). Mayoritariamente, la cobertura de las salidas se efectuaba desde Gibraltar, desde donde se reconocían las Islas Baleares y la costa meridional y oriental de la Península Ibérica y el norte de África.

\footnotetext{
7 The National Archives, Catalog Reference CAB/65/7/26. War Cabinet 131(40), pàg. 193 y ss.

8 National Archives Identifier 2147044. Record Group 165. Records of the War Department General and Special Staffs, $1860-1952$. College Park, Maryland (USA).
} 
A los vuelos de reconocimiento sobre las islas Baleares por parte de los aliados se les pueden asignar dos grandes objetivos:

- Información y vigilancia, porque lógicamente interesaba conocer el estado de la situación en las Islas (tránsito marítimo, movimientos de carácter militar y logístico, infraestructuras, defensas).

- Análisis territorial, que incluye los estudios previos de las Baleares como un posible escenario de acciones bélicas, así como la programación para una eventual ocupación.

La Tabla 1 muestra una recopilación de las salidas realizadas entre 1941 y 1943 a partir de la consulta de los informes de interpretación encontrados en los archivos históricos. A modo de ejemplo, se han seleccionado los informes de las salidas de reconocimiento sobre el puerto de Palma y los aeródromos de Son Bonet y Son San Juan en Mallorca.

Tabla 1. Salidas de reconocimiento aéreo realizadas entre el 21 de octubre de 1941 y el 31 de agosto de 1943 sobre el puerto de Palma y los aeródromos de Son San Juan y Son Bonet en Mallorca

\begin{tabular}{|c|c|c|c|c|c|}
\hline Fecha & $\begin{array}{l}\text { Número de } \\
\text { salida }\end{array}$ & $\begin{array}{l}\text { Número de los } \\
\text { fotogramas }\end{array}$ & Lugar & $\begin{array}{l}\text { escala aproximada } \\
\text { de la foto aérea }\end{array}$ & Información sobre el vuelo \\
\hline 21/10/1941 & $\mathrm{G} / 47$ & $\begin{array}{l}1145-1161 \\
2125-2145\end{array}$ & Palma & $1 / 15.000$ & $\begin{array}{l}\text { 14:00 hrs F.L. } 14 " \\
17.750 \text { pies "A" }\end{array}$ \\
\hline 21/10/1941 & $\mathrm{G} / 47$ & $\begin{array}{l}1107-1129 \\
2107-2087\end{array}$ & Son San Juan & $1 / 15.000$ & $\begin{array}{l}\text { 14:00 hrs F.L. } 14 " \\
17.750 \text { pies "A" }\end{array}$ \\
\hline 20/01/1942 & G/90 & $2-16$ & Palma & $1 / 17.500$ & 13:30 hrs F.L. 14" 20.500 pies "A" \\
\hline 20/01/1942 & $\mathrm{G} / 90$ & $1-98$ & Son San Juan & $1 / 17.500$ & 13:30 hrs F.L. 14" 20.500 pies "A" \\
\hline 20/01/1942 & G/90 & $2-94$ & Son San Juan & $1 / 19.000$ & 13:30 hrs F.L. 14" 20.500 pies "A" \\
\hline 20/01/1942 & G/90 & $2-29$ & Son Bonet & $1 / 19.000$ & 13:30 hrs F.L. 14" 20.500 pies "A" \\
\hline 21/01/1942 & G/91 & $2-18$ & Palma & $1 / 20.300$ & 13:45 hrs F.L. 14" 24.000 pies \\
\hline 21/01/1942 & G/91 & $2-13$ & Son Bonet & $1 / 20.300$ & 13:45 hrs F.L. 14" 24.000 pies \\
\hline 23/10/1942 & $\mathrm{G} / 211$ & & Palma & $1 / 15.000$ & \\
\hline 20/12/1942 & $\mathrm{WO} / 45$ & 1.33 & Palma & $1 / 9.700$ & F.L. 20" 16.200 pies 'A' \\
\hline 16/01/1943 & G/279 & 2044,2045 & Palma & $1 / 8.600$ & F.L. 20" 14.000 pies 'A' \\
\hline $18 / 01 / 1943$ & $\mathrm{G} / 281$ & $3013 / 15$ & Son San Juan & & \\
\hline 18/01/1943 & G/281 & 3019 & Son Bonet & $1 / 16.000$ & Oblícuas F.L.14" "A" foto \\
\hline 18/01/1943 & $\mathrm{G} / 281$ & 3011 & Palma & $1 / 16.000$ & 13:40; 14" Oblícuas "B" \\
\hline 21/01/1943 & G/285 & $\begin{array}{l}1.10,2099 \text { hasta } 2101, \\
1106,1107,2107\end{array}$ & Son Bonet & $1 / 9.200$ & 12:00 hrs. F.L.20" 15.500 'A' \\
\hline 21/01/1943 & G/285 & 2091, 2092, 2093 & Palma & $1 / 9.200$ & 12:00 hrs. F.L.20" 15.500 'A' \\
\hline 21/01/1943 & G/285 & $\begin{array}{l}1.121,2094,2095,2096 \\
1096,1097\end{array}$ & Son San Juan & $1 / 8.700$ & 12:00 hrs. F.L.20" 15.000 'A' \\
\hline 07/06/1943 & G409 & 3073,3074 & Son Bonet & $1 / 9.400$ & 13:15 hrs F.L. 20" 15.000 "A" \\
\hline 07/06/1943 & G409 & 4053,4054 & Son San Juan & $1 / 9.400$ & 13:15 hrs F.L. 20" 15.000 "A" \\
\hline 15/07/1943 & G442 & $3050,3052,4053,4055$ & Son San Juan & $1 / 9.700$ & D.A.R. 417 \\
\hline 15/07/1943 & G442 & $3059,3061,4062,4064$ & Son Bonet & $1 / 9.700$ & D.A.R. 417 \\
\hline 31/07/1943 & G461 & 3067,3068 & Palma & $1 / 9.600$ & F.L. 20" 16.000 "A" \\
\hline 10/08/1943 & G472 & 4121,4122 & Palma & $1 / 9.800$ & F.L. 20" 16.300 "A" \\
\hline 31/08/1943 & G486 & $4040,4041,4042$ & Palma & $1 / 9.000$ & F.L. 20" 15.000 "A" \\
\hline
\end{tabular}

Fuente: Documentos consultados en The National Archives de Londres (AIR 29/261-264). Elaboración propia

Los informes de los intérpretes de la RAF a Medmenham permiten disponer de mucha más información que la mostrada en un fotograma aéreo; por ejemplo la altitud del vuelo, en pies, la distancia focal de la cámara, F.L. en pulgadas, y la calidad de la fotografía, siendo la categoría "A" excelente. Además de estos datos técnicos, los intérpretes realizaban un informe secreto donde se anotaba toda la actividad que se observaba; si se disponía de alguna fotografía anterior, se comparaba con la última misión resaltando los cambios detectados. La información es muy detallada, incluyendo las medidas de los barcos más gran- 
des (M/V) o su tipología, la localización en el puerto y la actividad. Por ejemplo, en la salida G/91 del 21 de enero de 1942 sobre el puerto de Palma se dice:

There are no naval units present. Since the last sortie (G/90) the passenger Cargo Liner 250/300' has departed. The two M/V's 250/300' lying stern-to-quay at the NEW MOLE are still present: there are no sign of activity near these vessels. The coaster 150/200' which was a new arrival on G/90 is still lying off. A vessel 100/150' has arrived and is berthed stay-to-quay at the NEW MOLE in the inner harbour. The floating crane is still present in the inner harbour. There are no further significant changes to report since G/90 (Central Interpretation Unit, C.I.U., 1942. Interpretation Report MG77, p. 1).

En el caso de los dos aeródromos, Son San Juan y Son Bonet, se hace inventario de los tipos de aviones que se encontraban en los mismos. En el informe secreto de la salida G/90 del 20 de enero de 1942 sobre el aeródromo de Son San Juan se escribe: "11 aircrafts: 8 HE-11l's (old types), 1 probable Ju 52 with civilian markings, 1 medium single engined aircraft (uncamouflaged), 1 small aircraft" (C.I.U., 1942. Interpretation Report MG77, p. 2); y sobre Son Bonet se comenta que es la primera vez que el aeródromo se observa completamente: "This is the first time the aerodrom is fully covered. 11 aircrafts: 1 large, 7 medium, 3 small. 2 of the medium aircraft appear to be complete with engines and tails units while the remainder are without tail units" (C.I.U., 1942. Interpretation Report MG77, p. 2).

Figura 1. Detalle del puerto de Palma de la fotografía aérea vertical tomada el 20 de diciembre de 1942

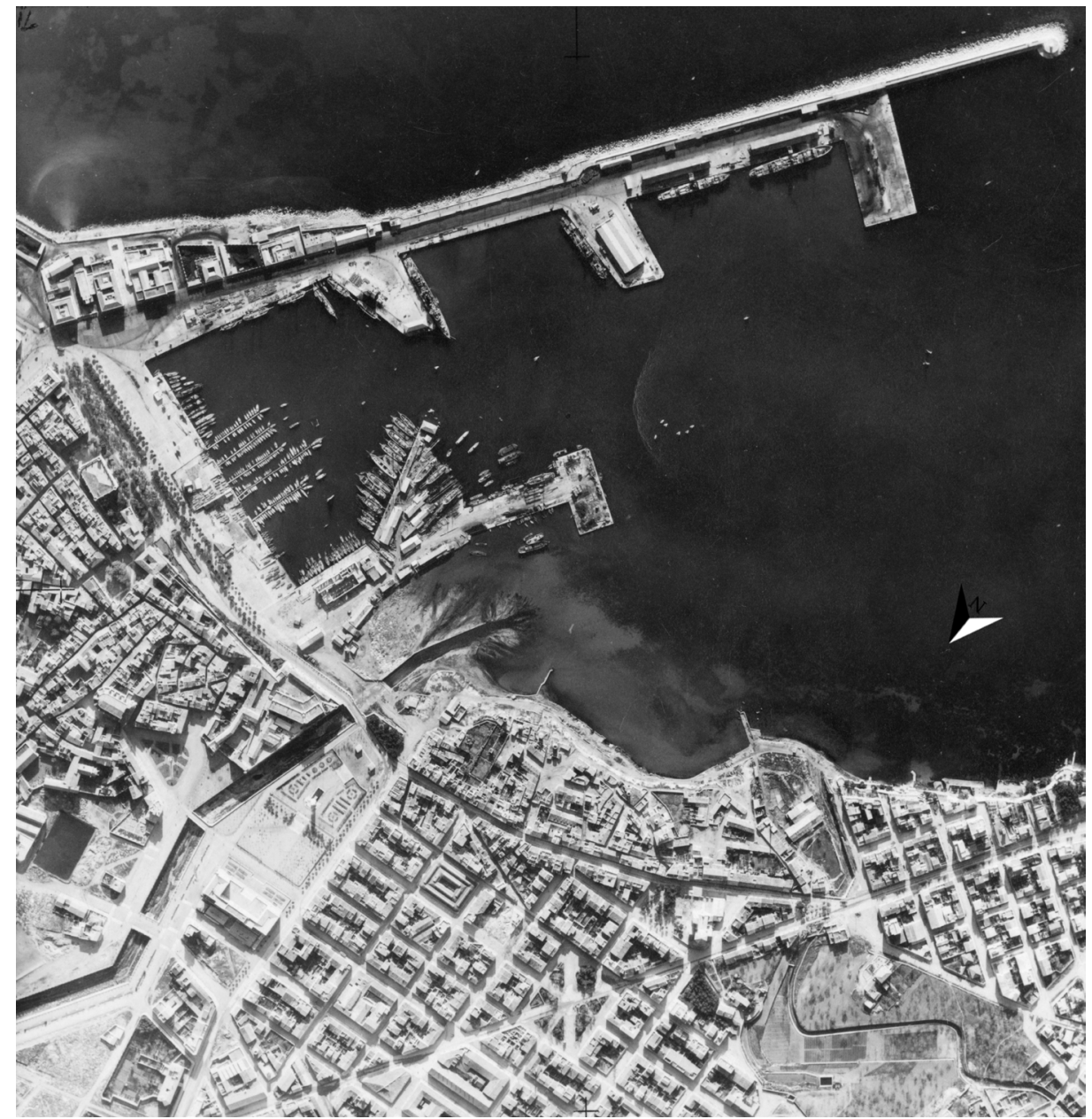

Fuente: National Collection of Aerial Photography (NCAP)

Además de esta información secreta que se pasaba a través de un informe donde se hacía constar la cantidad de copias hechas y a quien se distribuía (p.e.: Almirantazgo, Gabinete de Guerra, etc.) se incluía alguna copia de las fotografías analizadas. Un ejemplo de la calidad y detalle de estas fotografías aéreas se muestra en la Figura 1. En ella puede verse el puerto de Palma, uno de los más importantes 
del Mediterráneo occidental. Una característica histórica del mismo fue la distribución de la actividad portuaria en dos lugares separados: el Moll Vell, situado frente a la que antaño fuera una de las puertas de entrada a la antigua ciudad amurallada (Porta del Moll), y la cala de Portopí, a unos tres kilómetros. La fotografía del 20 de diciembre de 1942 muestra una gran parte de la ciudad de Palma y Santa Catalina, el Moll Vell, el puerto pesquero y las instalaciones existentes. Además, en el centro de la fotografía, la desembocadura del torrent de Sa Riera y todo el espacio del actual paseo marítimo sin construir. En el extremo inferior derecho de la fotografía, aún es visible el torrent de Sant Magí circulando en superfície entre los campos de cultivo; hoy en día se encuentra totalmente cubierto por las infraestructuras urbanas.

La fotografía aérea iba acompañada de esta detallada redacción reflejada en el informe:

JUPITER-class minelayer remains alongside the old Mole. Three merchant vessels over 200' present, all of which are new arrivals. The cargo liner 300/350' and the two M/Vs 250/300' have since departed. 1 M/V 300' approx.; 1 M/V 250/300' along the New Mole; 1 M/V 250/300' along the Old Mole. At least 15 sailing vessels 80/130' (C.I.U., 1943. Interpretation Report 4408, p. 1)

La fotografía original tiene una escala aproximada de 1/9.700. El minador Júpiter se observa con claridad en el muelle viejo, cerca de las embarcaciones de pesca.

La mayor parte de las actividades de reconocimiento aéreo se produjeron en unos momentos concretos del decurso de la guerra. Sobre todo cuando el conflicto ya había entrado en un punto de inflexión, después de la incorporación a la guerra de los Estados Unidos, cuando los aliados ya habían ocupado el norte de África y los alemanes habían comenzado a perder la iniciativa.

En aquellas circunstancias, considerando la no beligerancia del Estado español y la guerra a una escala europea, el papel estratégico de las islas Baleares ha de evaluarse desde dos perspectivas —que pueden parecer contradictorias, pero que no lo son, en función del desarrollo y de la evolución del teatro bélico-:

- Las Baleares podrían tener una importancia primaria, sobre todo como base logística y de soporte para posibles operaciones militares, tanto para la invasión de tierras continentales como para el control del área occidental del mar Mediterráneo.

- Al mismo tiempo, las islas Baleares podían pasar a tener una importancia secundaria, en la medida que, si no se producían acontecimientos contrarios a los intereses de los aliados, la atención prioritaria y los esfuerzos podrían dirigirse hacia otros lugares.

\subsection{Los informes especiales de interpretación de las fotografías aéreas}

Se han localizado los expedientes referidos a Mallorca, a Menorca y a Ibiza y Formentera. Los informes se basan en el análisis y la interpretación de fotografía aérea. Son el resultado de un análisis comparativo de fotografías aéreas de diferentes vuelos. Todo indica que los informes consultados substituían a otros informes precedentes. Los expedientes contienen indicaciones sobre cambios de informaciones previas o la no existencia de cambios observables respecto a misiones anteriores. (De momento, se desconoce si los documentos anteriores fueron destruidos o permanecen archivados).

Las pasadas fotográficas no siempre cubren todo el territorio de cada isla. Hay zonas no fotografiadas, pero - y esto es esencial para un espacio insular- el perímetro del litoral está cubierto en su totalidad. Algunas áreas son fotografiadas/observadas de manera reiterada, como las de interés estratégico, aeródromos, puertos o instalaciones militares. De todos modos, la descripción textual y la fotointerpretación trasladada a los mapas y a las fotografías ofrecen una valiosa información territorial del momento (19411945). Probablemente, se trata de la colección más antigua de fotografías aéreas verticales sobre las islas Baleares.

A pesar de ser el resultado de vuelos de reconocimiento aéreo (Information contained in this report is obtained from interpretation of air photographs only), los informes de Mallorca y de Menorca no incluyen fotografías aéreas. En cada caso, incorporan un mapa general de la isla para la localización de las zonas de cobertura del reconocimiento aéreo, especialmente el litoral, mientras que la información se expresa a través de la descripción textual. Se centra en las características de la costa, las baterías de costa y antiaéreas, los aeródromos y lugares de amaraje de hidroaviones, los puertos (y lugares de desembarco) y la actividad naval, los núcleos de población, la red viaria, puntos de interés militar e industrial, etc.

El expediente de Mallorca (C.I.U. Special Interpretation Report $n^{\circ}$ XY 30) es de 21 de febrero de 1943. Se fundamenta en la información recogida por diferentes salidas de vuelos, realizadas entre el 22 de 
octubre de 1941 y el 2 de febrero de 1943. Las imágenes fotográficas tenían un grado de resolución que oscila de una escala 1: 9.000 hasta una escala 1 : 18.000). ${ }^{9}$

El expediente de Menorca (C.I.U. Special Interpretation Report $n^{\circ}$ XY 31) es de 25 de febrero de 1943. Como en el caso de Mallorca, la información fue recogida por salidas de vuelos, entre el 22 de octubre de 1941 y el 2 de febrero de 1943. Las imágenes fotográficas tenían un grado de resolución desde una escala 1: 9.000 a una escala $1: 21.000){ }^{10}$

El expediente sobre Ibiza y Formentera (C.I.U. Special Interpretation Report $n^{\circ}$ XY 43. Ibiza and Formentera), de 5 de junio de 1943, es especialmente interesante, tanto por su contenido como desde el punto de vista de la fotointerpretación, porque usa esencialmente un lenguaje derivado del análisis de fotografía aérea, que se traslada a un mapa topográfico con leyenda o a las mismas fotografías:

Information contained herein is obtained from interpretation of air photographs only. It must not, therefore, be accepted as necessarily final and is liable to modification and amplification in the light of information from other sources available to the appropriate N.I.D., M.I. and A.I. branches.

This report is experimental in so far as the text as been mainly eliminated and an attempt has been made to show all essential matter gained from photographic interpretation either as overprints on maps or as annotations on photographs (C.I.U., 1943. Special Interpretation Report XY 43, p. 1).

Figura 2. Detalle del mapa topográfico G.S.G.S. 4376, escala 1:50.000 con la fotointerpretación sobre la zona sur de la isla de Ibiza, el actual parque natural de Ses Salines, incluido en C.I.U. Special Interpretation Report n ${ }^{\circ}$ XY 43 Ibiza and Formentera, de 5 de junio de 1943.

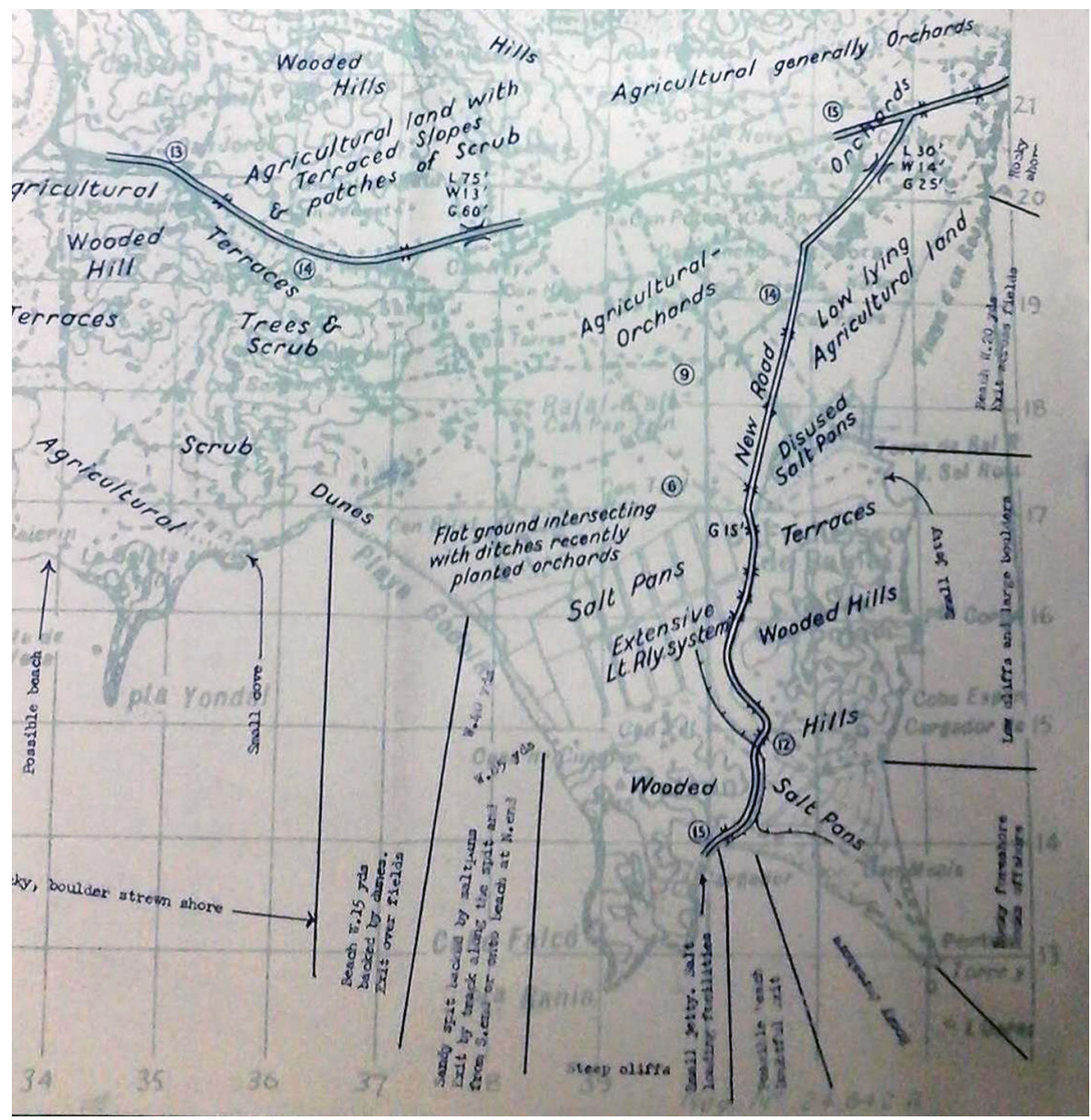

Fuente: The National Archives en Londres. WO 252/1037

9 The National Archives, WO 252/1029.

10 The National Archives, WO 252/1030. 
El informe de Ibiza y Formentera se basa en la información recogida por salidas de vuelos realizadas con anterioridad, desde el 22 de octubre de 1941 hasta el 22 de marzo de 1943. Las diversas imágenes fotográficas no sólo están actualizadas, sino que tienen un grado de resolución muy superior (desde una escala aproximada de 1:9.000 hasta una escala 1:20.600) a la de muchos de los mapas topográficos disponibles. ${ }^{11}$

La estructura del informe contiene el código de las salidas de los vuelos de reconocimiento y la localización de las pasadas en el mapa topográfico de referencia. Tiene una introducción, una interpretación de los puntos de artillería y una hoja de leyenda. Las fotografías aéreas con anotaciones y la información trasladada a diversas copias de mapas topográficos: en primer lugar, las zonas cubiertas y las correspondientes salidas de vuelo, juntamente con los mapas topográficos que contienen las notas de los resultados de la interpretación de las fotografías aéreas (Figura 2).

Two copies of each of the five maps covering the area have been made. One shows the type of coast, roads, bridges and general topography, overprinted in blue. The other shows defences and other military or industrial information, overprinted in red, and photographic cover, overprinted in green. The green overprints divide the maps into sections, inside each of which is shown the best available sortie over that section. The divisions are only approximate, but they indicate generally the dates of the information given and the areas which have not been photographed. (C.I.U., 1943. Special Interpretation Report XY 43, p. 2)

Las fotografías aéreas son en blanco y negro. En los mapas se usan diferentes colores. Verde: número de la salida y área fotografiada; azul: notas y comentarios de la fotointerpretación; rojo: puntos de interés militar, campos de aviación, baterías de costa y antiaéreas, torres de vigilancia, etc.

El máximo interés recae sobre las características del relieve del litoral (tipología de la costa, por ejemplo, low cliffs and rooks); las zonas de playa y sus dimensiones y si la playa tenía un acceso fácil a un camino o carretera (easy access to a road). Junto con las informaciones específicas sobre las capacidades defensivas o de carácter militar o industrial, pueden extraerse otros detalles, como si el área de costa había sido fotografiada o no; los usos del suelo, las zonas cultivadas y arboladas, los caminos y su anchura, además de aspectos generales del territorio.

\subsection{Utilidad de la fotografía aérea histórica para el estudio de la evolución del paisaje}

Sin duda, la utilidad geohistórica de las fotografías es de elevado interés. ${ }^{12}$ Los catorce años de antigüedad, respecto a la fotografía aérea de 1956, permiten conocer el territorio insular antes de las transformaciones que el desarrollo turístico produciría en las islas. Aunque, el aspecto más destacado es la excelente calidad de las fotografías y su escala, en muchos casos, aproximada a 1:9.500 (Tabla 1). Sin afán de exhaustividad, se ofrecen algunos ejemplos en las siguientes figuras.

Uno de estos ejemplos es el caso del humedal de ses Fontanelles (Figura 3), en el litoral del término municipal de Palma (Mallorca). La fotografía aérea de 1942 es la primera que da una visión integral de cómo era esa zona húmeda antes de su completo aislamiento y reducción por el crecimiento urbanístico del lugar. Este humedal formaba parte del antiguo humedal desecado del Prat de Sant Jordi (Rosselló Verger, 1959). Las inundaciones y la insalubridad llevaron a un proyecto final de desecado, realizado entre 1845 y 1849 por Paul Bouvij, que usaba molinos de viento que extraían el agua que era vertida a una red de canales y acequias que la transportaban a la zona más baja, localizada en el Arenal: ses Fontanelles. En la imagen puede verse el canal de desagüe de la acequia de Sant Jordi. En la fotografía de 1956 parte del humedal está seco y ya se ha iniciado el proceso de urbanización del margen izquierdo de la acequia, de aquí el valor ambiental de la fotografía de 1942. Hoy en día, lo que queda de humedal, sobrevive a toda la infraestructura hotelera y complementaria instalada en la zona, y a diversos proyectos que vienen proponiéndose desde la década de 1980 (parque de atracciones, circuito de karting y el más conocido centro comercial). ${ }^{13}$

La fotografía aérea también es un documento geomorfológico único, que permite observar en detalle un sistema playa-duna durante el invierno, con la acumulación de las hojas muertas de posidonia en la playa y el sistema dunar antes de su completa ocupación y posterior desaparición en la playa de Palma.

11 The National Archives, WO 252/1037.

12 En la exposición "Vigilados desde el cielo. 1939-1945. El papel estratégico de los puertos de Baleares durante la Segunda Guerra Mundial" se muestran algunas fotografías de los puertos de las islas Baleares y constituyen el testimonio del interés geoestratégico de estas imágenes aéreas (http://www.portsdebalears.com/sites/default/files/libros/QR_castella_BAIXA.pdf)

13 El proyecto de construcción de un centro comercial sobre ses Fontanelles se halla inmerso en una batalla judicial por la licencia de construcción, actualmente suspendida por sentencia del tribunal superior de justicia de las Baleares de junio 2020. 
Figura 3. Fotografía aérea de diciembre de 1942 de la zona húmeda de ses Fontanelles y estany Blanc, entre Can Pastilla y la Playa de Palma (isla de Mallorca)

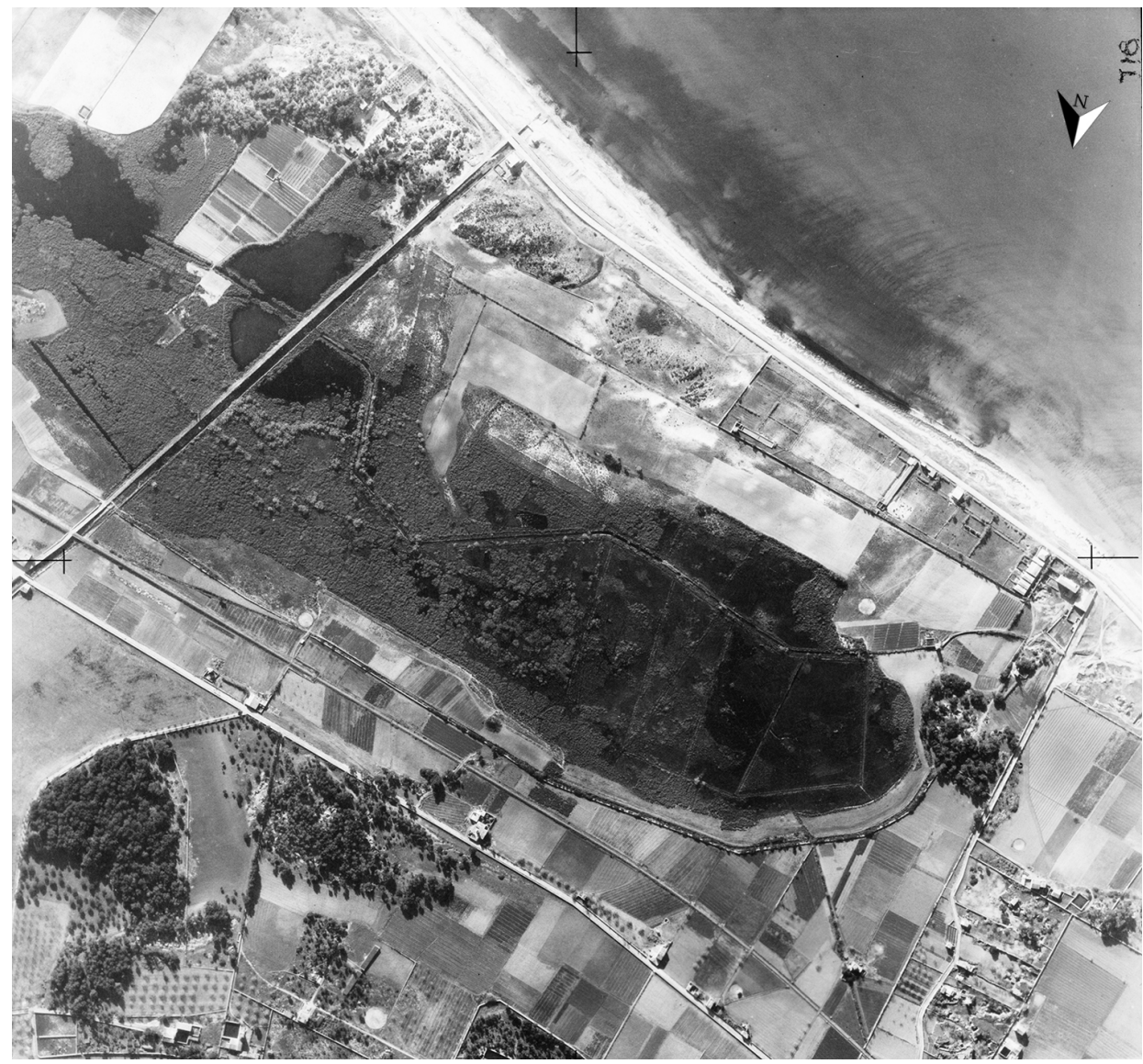

Fuente: National Collection of Aerial Photography (NCAP)

Otra de las imágenes, de gran valor geohistórico, es la tomada por la RAF el 19 de noviembre de 1941 sobre la isla de Formentera. En ella se observa el pequeño puerto de la Savina, las salinas d'en Ferrer para la producción de sal, y la carretera que va a Sant Francesc Xavier entre las lagunas salobres de Estany des Peix y Estany Pudent. Aunque lo que más sobresaliente es sin duda la colonia penitenciaria de Formentera (es Campament), que entró en funcionamiento en 1939 y se cerró en 1942, coincidiendo con el desembarco aliado en el norte de África (operación Torch) y para evitar que la opinión internacional conociera el deplorable estado en que vivían los prisioneros. Esta es la primera y única imagen aérea que existe de este centro de reclusión dependiente de la prisión provincial de Palma, que funcionó como campo de concentración de presos republicanos. Sus restos, así como la acequia de canalización que desemboca en el Estany des Peix, fueron declarados bien de interés cultural (BIC) en 2014. La calidad de la fotografía permite ver con detalle la distribución de los barracones e incluso a los presos que en ese momento se encontraban en el exterior. La imagen posibilita la recuperación de la memoria histórica de Formentera y del que fuera símbolo de la represión franquista contra los vencidos republicanos.

Finalmente, se reproduce un detalle de la fotografía aérea tomada el 10 de mayo de 1943 sobre el puerto de Mahón. Entre las numerosas fotografías realizadas en Menorca, el puerto de Mahón aparece de forma recurrente, centrándose su interés en las actividades desarrolladas en los muelles de la Base Naval. La fotografía fue tomada por el escuadrón 683 de la RAF en mayo de 1943 a unos 27.000 pies de altitud (escala aproximada de 1:9.000) y con distancia focal de 36 pulgadas. No obstante, el documento histórico sirve hoy para otra finalidad que es la de comparar el estado del núcleo urbano con la fotografía más conocida de 1956. Para evitar la distorsión en la lectura que provocan las sombras proyectadas por la topografía y por la volumetría urbana se han reorientado ambas fotografías. El detalle se enmarca entre la línea de la fachada marítima y las huertas interiores de Es Freginal, en el eje norte-sur y entre la iglesia de San Francisco y una parte del distrito Tanques del Carme, en el eje oeste-este respectivamente. 
Figura 4. Fotografía aérea del 19 de noviembre de 1941 de la zona del puerto de la Savina (parte inferior), el Estany des Peix (izquierda de la foto) y el Estany Pudent, en la isla de Formentera.

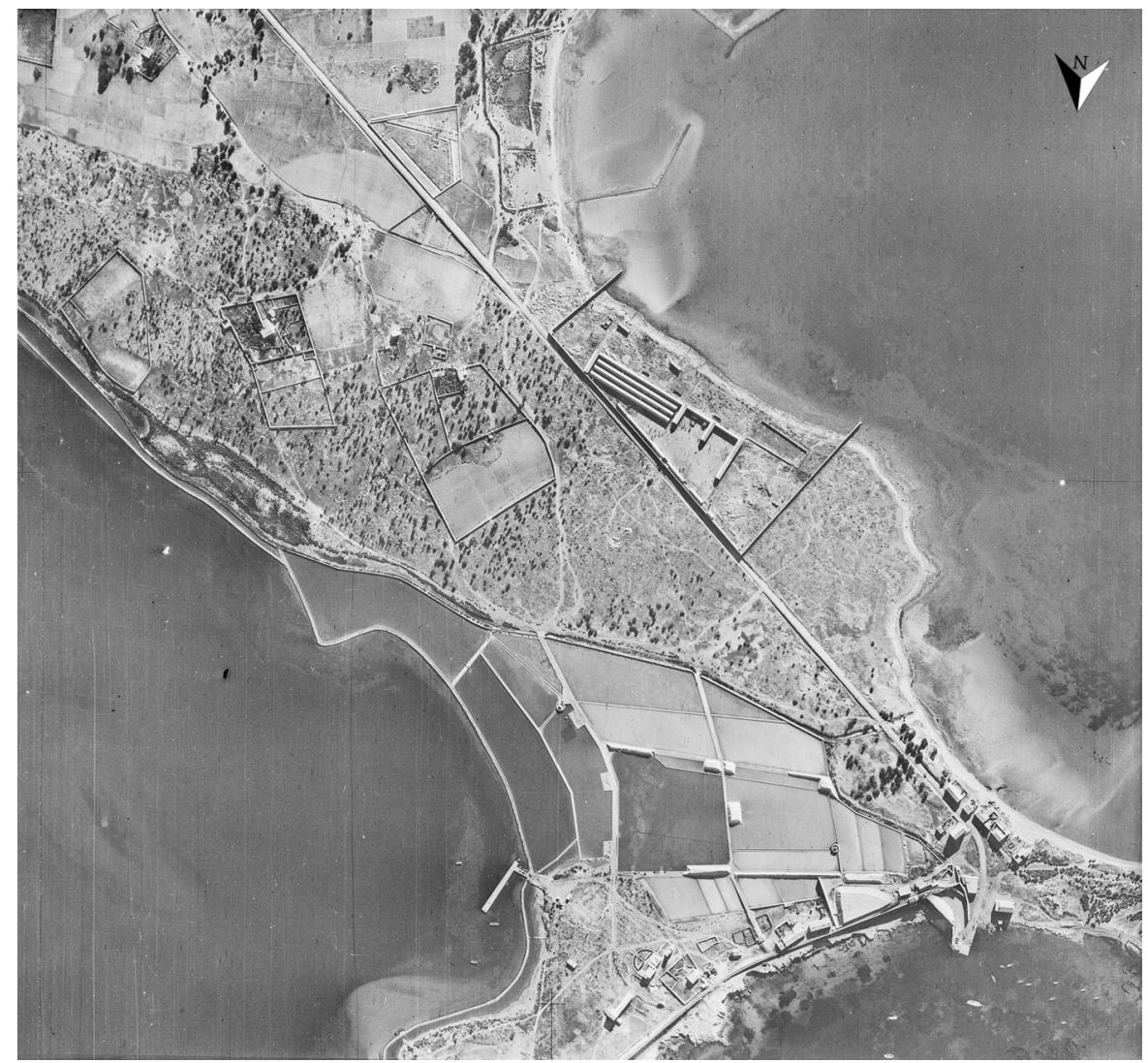

Fuente: The National Archives and Records Administration (NARA). Record Group 373

Figura 5. Fotografía aérea del 10 de mayo de 1943 del puerto de Maó. Detalle de la ciudad en comparación con la fotografía de 1956

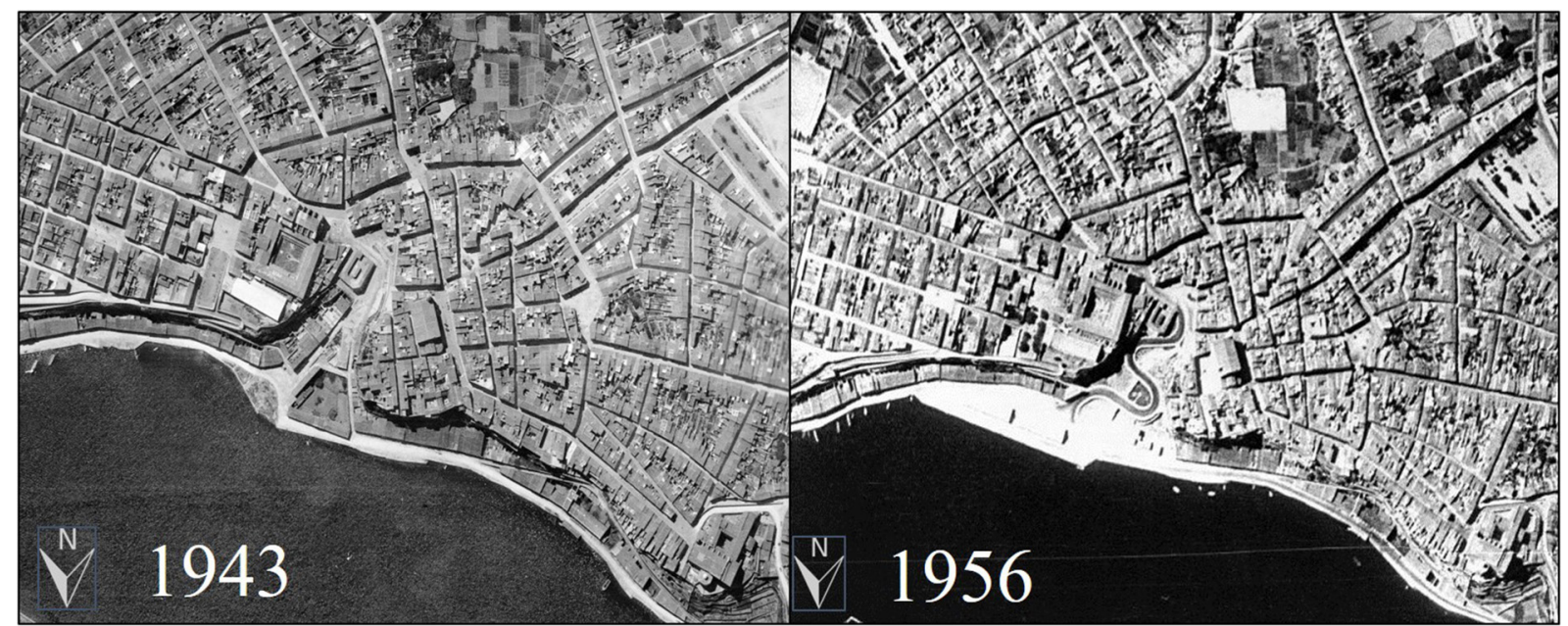

Fuente: The National Archives and Records Administration (NARA, Record Group 373) y Ortofotografia 1956 de las islas Baleares

(SITIBSA-SCNE-CECAF)

El hecho más relevante lo constituye sin duda que la fotografía realizada por la RAF inmortaliza la disposición urbana de Mahón sólo un año antes de que aprobara e iniciara su ejecución el Proyecto de Reforma Interior y Ensanche de Mahón, del arquitecto municipal Josep Maria Claret, primer documento urbanístico de la ciudad. En efecto, en 1944 se derribaron ya las casas que integraban la manzana de vi- 
viendas sobre cuyo solar se abrió la plaza de la Conquista. Se observa también con claridad en la imagen de 1943 la conocida como cuesta de la Abundancia, la rampa que conectaba la parte alta de la ciudad con el puerto, convertida en 1951 en la costa de la Victoria, actualmente costa de Ses Voltes. Puede observarse también la ampliación de los muelles comerciales del espacio portuario, en especial del andén de Levante.

\section{Discusión de resultados}

La consulta en los archivos británicos de la documentación de las misiones de los vuelos de reconocimiento aéreo de los aliados permite confirmar la existencia de planes específicos para la invasión de las islas Baleares, con informes que planifican geográficamente los puntos clave para lograr un ataque efectivo, que fue perfectamente posible. El gobierno franquista veía con gran preocupación la posibilidad de un ataque desde el exterior o la invasión de las Baleares, que tanto podía proceder de Italia o Alemania, como de cualquiera de los países aliados: Francia, Reino Unido o Estados Unidos. Por este motivo, desde el final de la guerra civil se procedió — en la medida de las posibilidades - a reforzar las defensas en todas las islas, sobre todo en la costa (Rodrigo Fernández, 2014). Así mismo, a causa del desembarco aliado en Marruecos y Túnez, se llevó a cabo una movilización de soldados a finales de 1942.

La importancia geoestratégica de Baleares era evaluada por todas las partes beligerantes, igual que desde la perspectiva española. El general Alfredo Kindelán, comandante general de las islas Baleares (1939-1941), consideraba que el triángulo Mahón-cabo de Creus (Gerona)-cabo de Sant Antoni (Alicante) era "un mar español" y que su control aportaría una posición de supremacía aeronaval a quien lo controlara. Las Baleares podían asegurar el triángulo entre Palma, la bahía de Roses (Girona) y el cabo de Sant Antoni, mediante el establecimiento de una base aérea en Mallorca —un auténtico portaaviones insumergible- y con la presencia de destacamentos navales en el puerto de Palma, constituyendo Menorca e Ibiza las otras bases de apoyo (Rodrigo Fernández, 2014). El refuerzo tanto de las defensas costeras como de los aeródromos pretendían garantizar la supervivencia de las islas en caso de prolongados bloqueos. Por ello, desde la finalización de la guerra civil se instaron obras de fortificación, revisión del estado de las baterías o construcción de nidos de ametralladora, junto con otras dotaciones, sobre todo para reforzar las playas y las zonas del litoral que pudieran ser objeto de un desembarco. A pesar de todo, a causa de las carencias y del estado de precariedad en que se hallaba el ejército español, parece que las capacidades para evitar una invasión de las islas eran muy limitadas.

Los temores a una invasión fueron persistentes durante los primeros años de 1940. El 5 de mayo de 1940, proliferaban los rumores de una posible ocupación británica de Ibiza en el supuesto de que Italia entrara en guerra. El 3 de junio de 1940, cobra fuerza la idea de una ocupación inminente de Mallorca por parte de Italia con ayuda alemana. No obstante, la población isleña un año después (marzo de 1941), se muestra en realidad más preocupada por la provisión de alimentos que por la guerra (Buades, 1999).

A causa de la importancia de Mallorca como base aeronaval (mayor que la asignada a Menorca), en el año 1943, el británico Lawrence Dundas, considerando que Franco era una marioneta de Hitler, propugnó la conquista de Mallorca por parte de los aliados, antes de la invasión de Italia; políticamente, el supuesto era que la población isleña recibiría a los británicos como liberadores (Dundas, 1943).

Las fotografías aéreas fueron esenciales para las estrategias militares en la segunda guerra mundial; servían para controlar la ubicación y los movimientos de las tropas y vehículos, y para localizar las instalaciones que serían objetivo de los bombardeos. Es evidente que la primera guerra mundial sirvió de catalizador para integrar la cámara y el avión como un sistema coherente (Campbell 2008). La capacidad de posicionar un avión sobre la zona a fotografiar era la clave para producir fotografías para elaborar mapas. Al comienzo de la primera guerra mundial se comprendieron los principios básicos, aunque los aviones y las cámaras eran todavía bastante primitivos. Al final de la guerra, Gran Bretaña contaba con una amplia capacidad de reconocimiento aéreo, posiblemente la más eficaz, si no la más avanzada técnicamente, de todas las naciones combatientes (Collier, 2006).

La contribución cartográfica más importante fue el desarrollo y la aplicación de los principios fotogramétricos para el levantamiento preciso de grandes regiones. Aunque las empresas privadas de esta época invirtieron en cartografía aérea civil, sus contribuciones se centraron a menudo en la adquisición y extracción de detalles planimétricos más que en los temáticos. Durante la segunda guerra mundial, el papel del reconocimiento aéreo se expandió desde un enfoque puramente táctico al ámbito de la estrategia, asumiendo un alcance mucho más amplio tanto geográficamente (profundizando en el territorio hostil) 
como teóricamente (buscando un conocimiento más profundo de la naturaleza de la infraestructura económica y de transporte del enemigo). Los avances más visibles durante esta guerra fueron los equipos especializados y los programas de entrenamiento sistemático. Sin embargo, la institucionalización del reconocimiento aéreo y la inteligencia fotográfica fueron los cambios más importantes (Collier, 2015)

La planificación y control de las actividades en el archipiélago balear se fundamentó en los vuelos de reconocimiento aéreo. Las fotografías aéreas encontradas y los informes de reconocimiento demuestran que los británicos utilizaron vuelos estereoscópicos, aspecto apuntado por Fernández García (2015) para el litoral andaluz. De hecho, el vuelo con número de salida G/47, del 21 de octubre de 1941 realizado por la primera unidad de reconocimiento fotográfico (PRU-Photographic Reconnaissance Unit), como el WO/45, del 20 de diciembre de 1942 realizado por la unidad 4 de la PRU, cubre Palma y su litoral hasta el aeropuerto de Son San Juan con una serie de fotografías verticales que se solapan. Además, la información que se dispone sobre la Unidad Central de Interpretación (C.I.U.), instalada en 1941 en Medmenham, confirma que fue el principal centro de interpretación de las operaciones de reconocimiento fotográfico realizadas sobre el continente europeo, norte de África, el Atlántico y el Mediterráneo. Las imágenes muestran a mujeres y hombres con estereoscopios interpretando las imágenes. El análisis detallado de formas, tamaños, sombras y firmas (patrones asociados con actividad específica) marcó la diferencia en las técnicas de interpretación de los aliados (Stanley, 1998). Su trabajo se ha considerado tan o más importante para el resultado de la guerra que el realizado en Bletchley Park descodificando los mensajes encriptados que utilizaban los ejércitos del Eje (Downing, 2011). Medmenham se convirtió en el hogar de una gran variedad de expertos, destacados en muchos campos: civiles del mundo científico y artístico se pusieron el uniforme aportando una serie de habilidades, el conocimiento y la experiencia que adaptaron al uso de la inteligencia militar. Además, con una mayor igualdad de la que normalmente disfrutaban en la vida civil, las mujeres tuvieron un papel crítico en una unidad que se parecía más a las universidades de Oxford y Cambridge que a un equipo de inteligencia secreta (Williams, 2013).

Y esto fue clave en el desarrollo de la guerra puesto que los alemanes, aunque disponían de mejor tecnología, como el film ancho de 11,8 pulgadas, y sus profesionales de reconocimiento fotográfico habían sido pilotos durante la primera guerra mundial, centralizaron la fotografía aérea civil y militar en el mismo departamento pero nunca fue ni supervisada ni promocionada a instancias superiores (United States. War Department. Military Intelligence Division, 1984). La organización de las unidades de reconocimiento aéreo de la Luftwaffe alemana siguió vinculada a la política de compartimentación característica del sistema nazi. Goering no dio tanta importancia a la interpretación fotográfica y, consecuentemente, la rama de inteligencia de la Luftwaffe tuvo muy poca libertad para mejorar tecnológicamente y se vio severamente limitada por el requisito de apoyar operaciones tácticas terrestres (Kostka, 2012).

La calidad de la fotointerpretación marcó la diferencia. Los alemanes hicieron lectura de fotos durante toda la guerra, marcando en ella lo que era más evidente. Este enfoque contrastaba con el análisis de la importancia de lo que detectaba en la fotointerpretación de los aliados. Los alemanes nunca usaron la cobertura estereoscópica porque no estaban entrenados para adquirirla o explotarla. Utilizaron exclusivamente impresiones individuales de las fotografías (Babington-Smith, 1957; McAuley, 2005).

El interés geoestratégico de las Baleares también se vio reflejado en la rapidez con la que se publicó el mapa de las Baleares del Army Map Service, con edición de Mayo de 1943 (Urteaga et al. 2000). Las 21 hojas de la serie completa a 1:50.000 fueron parcialmente actualizadas con los vuelos de reconocimiento de la RAF de 1941, 1942 y 1943; apareciendo en un recuadro inferior situado a la izquierda (reliability diagram) la zona revisada con fotografías aéreas. Aunque también los tres mapas 1:100.000 de las islas Baleares del Geographical Section, General Staff (G.S.G.S.): 4134 Menorca, 4373 Mallorca y 4376 Ibiza \& Formentera, en su segunda edición de 1942 para Menorca y de 1943 para Ibiza \& Formentera, reproducen el Reliability Diagram, esta vez en un recuadro a la derecha donde se marca el área revisada con información del servicio de inteligencia.

\section{Conclusiones}

Sin duda, el objetivo de los vuelos de reconocimiento y de la fotointerpretación era conocer el terreno para una invasión, prestando atención a las características del litoral y, especialmente, a si las playas eran aptas para el desembarco de tropas de infantería y si tienen acceso a vías de comunicación. 
Toda esta documentación es útil para confirmar la posibilidad real de una ocupación aliada de las Baleares, aunque las circunstancias de la guerra eran muy variables. En cualquier caso, sin duda, entre febrero y junio de 1943, el alto mando aliado había sopesado la posibilidad de ocuparlas militarmente.

En cambio (ya se ha citado el estudio, nota 8, de 12 de diciembre de 1942, para planificar una ocupación aliada de la Península Ibérica), en caso que las fuerzas del Eje atacasen a los aliados a través de España, se descartaba la posibilidad de ocupar las Baleares por medio de un asalto, a pesar de que los aliados también se proponían estudiar el traslado de fuerzas aéreas a las Baleares (incluso con el beneplácito del gobierno español). En realidad, toda esta planificación se llevaba a cabo en unos momentos en que los aliados conocían los síntomas de la debilidad de las fuerzas del Eje. De hecho, el 12 de julio de 1943, los británicos consideraban muy poco probable una ocupación alemana de las Baleares (Buades, 1999, pp. 112-113).

La posible ocupación aliada de las islas Baleares no se produjo. Por contra, después de haber ganado el norte de África, la invasión aliada de Italia comenzó por Sicilia (julio de 1943) y continuó a la Península Italiana (setiembre de 1943), sin necesidad de ocupar las Baleares por parte de los aliados. Una de las consecuencias de la rendición de Italia (1943) en las islas Baleares fue el hecho de que diversos buques italianos se refugiaron en el puerto de Mahón, donde quedaron internados hasta el final de la guerra.

A pesar de todo, siguieron las salidas de reconocimiento desde Gibraltar con destino a las Baleares hasta que acabó la guerra mundial, aunque con menor frecuencia (hay constancia de vuelos en agosto de 1943 y marzo de 1944). Por ejemplo, en el año 1944, uno de los enclaves que preocuparon a los aliados fueron las instalaciones y actividades de la base de hidroaviones de Pollensa (Mallorca).

Cabe destacar la fotointerpretación y el esfuerzo cartográfico llevado a cabo por las fuerzas aliadas a través de los múltiples vuelos realizados esos años, centralizado en la Unidad Central de Interpretación (CIU) en Medmenhan. La información obtenida era utilizada con objetivos militares pero también sirvió para mejorar y actualizar la cartografía disponible en aquel momento. Desgraciadamente, muchas de esas fotografías aéreas fueron destruidas una vez acabada la segunda guerra mundial. Se estima que entre 1941 y 1945 la biblioteca de Medmenhan tenía unos cinco millones de imágenes con las que se habían elaborado unos 40.000 informes. Se calcula que al final de la segunda guerra mundial se habían acumulado unos 36 millornes de fotografías aéreas de todo el mundo. Sólo una pequeña parte se conservó.

Este trabajo demuestra la importancia y utilidad de la fotografía aérea histórica para el estudio de los paisajes y sus dinámicas recientes. Actualmente, estos fotogramas históricos son de gran interés, porque, mediante la georeferenciación y la comparación con otras fotografías aéreas, hacen posible estudios geomorfológicos (línea de costa, sistemas playa-duna, relieve), biogeográficos (vegetación, zonas húmedas), de usos del suelo, de cultivos, de la red viaria, de las infraestructuras (puertos, aeropuertos, etc.), de la evolución urbana, o, incluso, de los primeros hoteles e instalaciones turísticas.

\section{Agradecimientos}

Los comentarios realizados por dos revisores anónimos han permitido mejorar considerablemente la versión final del artículo. Gracias por el esfuerzo y las revisiones tan detalladas.

\section{Financiación}

Este artículo se realiza gracias al contrato de investigación firmado con la Autoridad Portuaria de Baleares titulado: La fotografía aérea de 1942 sobre las islas Baleares.

\section{Referencias}

Aldrich, R.J. (1998). Espionage, Security, and Intelligence in Britain, 1945-1970. Manchester: Manchester University Press.

Babington-Smith, C. (1957). Air Spy: The Story of Photo Intelligence in World War II. New York: Harper \& Brothers.

Boyd, R.J. (2016). Project Casey Jones: Post Hostilities Aerial Mapping: Iceland, Europe and North Africa from June 1945 to December 1946. PennState Hazeltn Campus, EEUU. 
Buades, J. M. (1999). Les fonts britàniques per a l'estudi dels anys de la Segona Guerra Mundial a les Illes Balears. La vida quotidiana. Mayurqa, 24 (1997-1998), 101-116.

Campbell, J. B. (2008). Origins of Aerial Photographic Interpretation, U.S. Army, 1916 to 1918. Photogrammetric Engineering \& Remote Sensing, 74, 77-93. https://doi.org/10.14358/PERS.74.1.77

Collier, P. (2006). The work of the British Government's Air Survey Committee and its impact on mapping in the Second World War. The Photogrammetric Record, 21(114), 100-109. https://doi.org/10.1111/ j.1477-9730.2006.00368.x

Collier, P. (2015). Photogrammetric mapping. Air Photos and Geographic Analysis. In M. Monmonier (Ed.), Volume Six Cartography in the Twentieth Century (pp. 1113-1116). Chicago: University of Chicago Press.

Downing, T. (2011). Spies in the sky: the secret battle for aerial intelligence during World War II. Abacus.

Dundas, L. (1943). Behind the Spanish Mask. London: Robert Hale.

Fernández García, F. (2012). Un vuelo del litoral andaluz de 1942-1943. Ería, 87, 39-49.

Fernández García, F. (2015). Fotografía aérea histórica e historia de la fotografía aérea en España. Ería, 98, 217-240. https://doi.org/10.17811/er.98.2015.217-240

Fernández García, F. y Quirós Linares, F. (1997). El Vuelo Fotográfico de la Serie A. Ería, 43, 190-198.

Fioravanzo, M., Bauerkämper, A. y Rossoliński-Liebe, G. (2017). Italian Fascism from a Transnational Perspective: The Debate on the New European Order (1930-1945). In A. Bauerkämper \& G. Rossoliń ski-Liebe (Eds.) Fascism without borders: Transnational connections and cooperation between movements and regimes in Europe from 1918 to 1945 (pp. 243-263). https://doi.org/10.2307/j.ctvw04hnr.13

Kostka, Del C. (2012). Air Reconnaissance in the Second World War. Military history online. Recuperado de http://www.militaryhistoryonline.com/wwii/articles/airrecon.aspx

Liddell Hart, B.H. (1939). Axis Plans in the Mediterranean. An Analysis of German Geopolitical Ideas on Italy, France, Balearic Islands, Gibraltar, Catalonia and Spain. London General Press.

McAuley, C. (2005). Strategic Implications of Imagery Intelligence. Strategy Research Project. U.S. Army War College, Carlisle Barracks, Carlisle, PA.

Massot i Muntaner, J. (1995) El cònsol Alan Hillgarth i les Illes Balears. Barcelona: Publicacions de l'Abadia de Montserrat (Biblioteca Serra d'Or; 142).

Paci, D. (2013). Il mito del Risorgimento mediterraneo. Corsica e Malta tra politica e cultura nel ventennio fascista. (Tesis Doctoral). Università di Padova. Padova. Recuperado de http://paduaresearch.cab. unipd.it/5452/

Rodrigo Fernández, R. (2014). La defensa de las Islas Baleares durante la primera fase de la segunda guerra mundial (1939-1940). Revista Universitaria de Historia Militar, 3(5), 143-164.

Roselló Verger, M. (1959). El Prat de Sant Jordi y su desecación. Boletín de la Cámara de Comercio, Industria y Navegación de Palma de Mallorca, 622, 1-10.

Stanley, R.M., II (1998). To Fool a Glass Eye: Camouflage versus Photoreconnaissance in World War II. Washington: Smithsonian Institution Press.

United States. War Department. Military Intelligence Division (1984). German military intelligence, 1939-1945. Frederick, Md.: University Publications of America.

Urteaga, L., Nadal, F. y Muro, J.I. (2000). Los mapas de España del Army Map Service, 1941-1953. Ería, $51,31-43$

Williams, A. (2013). Operation Crossbow: The Untold Story of the Search for Hitler's Secret Weapons. Londres: Random House. 